\title{
Optimization of Bi-level Distribution Network System Based Fuzzy Multi-objective Decision-making Model Analysis
}

\author{
Sha LI ${ }^{1, a,{ }^{*}}$, Zhi-Gao LIAO ${ }^{1, b}$ Jie-Hong HUANG ${ }^{1, c}$, Nai-Chuan HUANG ${ }^{1, d}$ \\ ${ }^{1}$ Guangxi University of Science and Technology China department of management LiuZhou 545006

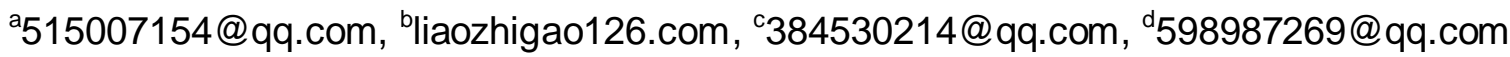 \\ ${ }^{*}$ Corresponding author
}

Keywords: distribution network, fuzzy demand, cost control, Excel

\begin{abstract}
We research a bi-level distribution network system consisted by a manufacturer, and several distribution centers and distribution points of the distribution system, taking into account transportation costs, and the cost of goods, inventory costs, optimize the distribution network, has established a relatively comprehensive distribution network cost model, and in the distribution center for point of contact, the distribution network is divided into two tour for discussion: upstream from the manufacturer and distribution center, and the two sides discussed a total cost model, downstream main distribution costs are minimized. The demand is not determined by the model, the use of instance Excel planning solver the solver to analyze optimized distribution network, and based on the relevant information to the results from the model of the inventory cost and the cost of goods, and to proceed with analysis of inventory control, and identifying ways to reduce the cost of goods, to further the distribution network fuzzy multi-objective decision-making model clarity, increase supply chain stability, to achieve distribution network design optimized for reference conditions.
\end{abstract}

\section{Introduction}

With the changes of people's demand and the increasingly fierce competition, the traditional supply chain management will be broken. Since the 1980s, supply chain management hasn't merely focus on the failure management of purchase and manufacturing sector any longer.Instead,we will stress emphasis on minimizing the supply chain network gross cost as well, which makes customer demand the overall driving factor of the entire supply chain. The core factor of enterprises is not the production but supply, which makes value grow through the distribution network and services. However, the traditional analysis network model is no longer adapted to consumer's need.Therefore, it's an important channel to strengthen the management of distribution link for improving customers' satisfaction and sharpening the competitive edge under the circumstances of consumer driven competition.

The Level II distribution network design optimization is a hotspot both at home and abroad. The reference [1] conducts research mostly on the demand and the supply-chain, multi-vendor, multi-product, multi-client distribution of optimizing the network design issues, And, taking the needs of the distribution into account, the distribution and distribution network of the Optimization model, thereby, will ultimately find the minimal cost of supply chain through optimizing the network structure and seeking the best distribution strategy to use algorithm model based on mixed genetic. Traditional distribution network system of research is to determine information for modeling optimization, which has reached distribution network costs overall. However, changes of the times, study to determine the information gradually being replaced by uncertain information, distribution network in random and ambiguous factors of uncertainty in today's changing market environment has emerged. Literature [3] studied the random distribution network, the multi-product and multi-level Supply Chain network analysis, a random-based demand of the multi-level Supply Chain network optimization model. the level 4 Supply Chain System emulation experiments, in a non-linear mixed integer mathematical approach to planning the cost of the supply chain.Literature [2] also studied the secondary distribution network optimization, stochastic programming model design. This paper consider the demand and the production capacity of the plant randomness characteristics of the 
product, set random parameters and use stochastic simulation based on genetic algorithms to solve the model and numerical examples which are given to illustrate the effectiveness of the model and algorithm.

In fact, the factory's production capacity and the demand of the product do not only have a random character but more ambiguous. Based on the former study, the same type of drag on demand supply chain research on multi-echelon distribution network distribution centers and multiple distribution points were analyzed fuzzy multi-objective decision model based on demand, in view of the lack of distribution points cost of goods, the establishment of an appropriate number of distribution centers, research distribution network in transportation costs, inventory costs and total cost of the construction of distribution centers and other factors, the design and optimization of the distribution network, to further improve customer satisfaction.

\section{Basic assumptions and Symbol description}

Distribution network consists of one manufacturer $\mathrm{M}$, several distribution center $\mathrm{D}$, as well as a number of distribution points $\mathrm{P}$ composition. Retailing demand triggering overall system, the manufacturer production product, ships to the retailing center, again assigns in the retailing the cargo for each retailing spot. As Chart (1)

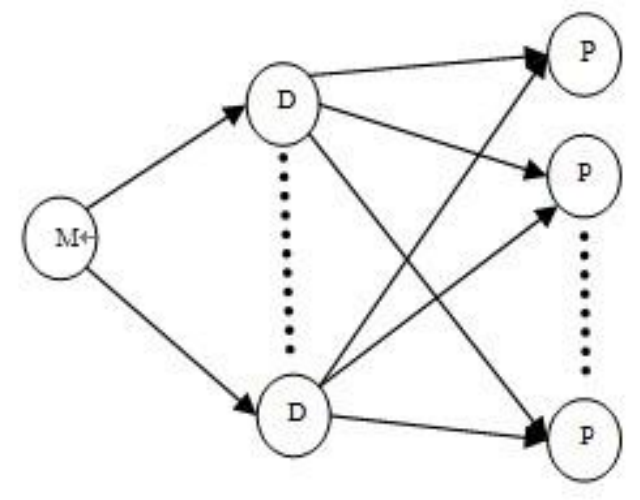

\section{Supposition 1}

Distribution Center No Cost of Goods, i.e. the manufacturer for the distribution center for the adequate, but the distribution center to the distribution point distribution of goods is encountered. When information asymmetries, is not timely issue, and so on, so that distribution is not immediately available, resulting in distribution, which is the cost.

\section{Symbol description}

M Manufacturer, $D_{k}$ Distribution center $(k=1.2 \ldots), P_{j}$ Retailing spot $(j=1.2 \ldots), I \quad$ Product $(1.2 \ldots . .),. \alpha_{\mathrm{Mi}} \quad$ Product ' volume efficiency made by Manufacturer , $\beta_{\mathrm{Mi}}$ Product ' resources coefficient made by Manufacturer , $\gamma_{\mathrm{Di}}$ Product ' resources coefficient made by Distribution centre, $\mathrm{a}_{\mathrm{Mi}}$ The production cost factor, $\mathrm{b}_{\mathrm{MDi}}$ Products' transport cost coefficient from manufacturers to distribution centers, $\mathrm{b}_{\mathrm{Dpi}}$ Product' transport cost coefficient from retailing center to retailing, $\mathrm{h}_{\mathrm{Di}}$ Product 'inventory holding cost factor in Distribution Center, $\mathrm{h}_{\mathrm{Pi}}$ Product 'inventory holding cost factor in Retailing spot, $\mathrm{f}_{\mathrm{P}}$ The shortage cost coefficient of distribution points, $\mathrm{f}_{\mathrm{d}}$ Establish a costs of distribution center, $\mathrm{y}_{\mathrm{d}=1}$ If the distribution is open, otherwise $0, \mathrm{~L}_{\mathrm{MD}}$ The transport delays from manufacturers to distribution centers, $\mathrm{L}_{\mathrm{DP}}$ The transport delays from the distribution center to the Distribution Point , Kd Potential distribution in the distribution center, $\mathrm{Z}_{\mathrm{M}}$ Manufacturer's production capacity, $Q$ Available resources, $R_{D}$ Distribution Center 'inventory capacity, $C_{D}$ Total cost of a new distribution centre, $X_{\mathrm{Dpi}}$ Distribution points on the demand for products from distribution center, $\mathrm{X}_{\mathrm{MDi}}$ Manufacturer's product demand in distribution center, $\mathrm{Y}_{\mathrm{Mi}}(\mathrm{t})$ At time $\mathrm{t}$ manufacturers' production capacity, $\mathrm{Y}_{\mathrm{Di}}(\mathrm{t})$ At time $\mathrm{t}$, the number of products in distribution centers, $\mathrm{Y}_{\mathrm{Pi}}(\mathrm{t})$ At time $\mathrm{t}$, the amount of product distribution, $\mathrm{Y}_{\mathrm{Di}}(\mathrm{t}-1)$ At time $\mathrm{t}-1$, Original distribution 
center' inventory, $\mathrm{Y}_{\mathrm{Pi}}(\mathrm{t}-1)$ At time $\mathrm{t}-1$, Original inventory in distribution points, $\mathrm{H}_{\mathrm{MPi}}\left(\mathrm{t}-\mathrm{L}_{\mathrm{MD}}\right)$ Freight volume from the manufacturer to the distribution center products, $\mathrm{H}_{\mathrm{Dpi}}\left(\mathrm{t}-\mathrm{L}_{\mathrm{DP}}\right)$ Freight volume from the distribution center to a distribution point, $\mathrm{F}_{\mathrm{Pi}}$ the number of distribution centre 'product that Distribution point lacks

\section{Model establishment}

The distribution network for upstream-downstream two-part discussion, relying on distribution center mutual contact: upstream is from the manufacturer and distribution center, and downstream the distribution center and distribution points. The two-part model is as follows.

\section{Manufacturers and Distributors center Model}

$\operatorname{Min} \mathrm{Z}_{M D}=\sum_{\mathrm{i}=1}^{\mathrm{I}} \sum_{\mathrm{k}=1}^{\mathrm{D}} \mathrm{a}_{M i} * \mathrm{X}_{M D i}+\sum_{\mathrm{i}=1}^{\mathrm{I}} \sum_{\mathrm{k}=1}^{\mathrm{D}} \mathrm{b}_{M_{D i}} * \mathrm{H}_{M D i}\left(t-L_{M D}\right)+\sum_{\mathrm{i}=1}^{\mathrm{I}} \sum_{\mathrm{k}=1}^{\mathrm{D}} h_{D i} * Y_{D i}(t)+\sum_{\mathrm{k}=1}^{\mathrm{D}} f_{d y} d$

In which $Y_{D i}(t)=H_{M D i}\left(t-L_{M D}\right)+Y_{D i}(t-1)-H_{D P i}\left(t-L_{D P}\right)$.

subject to

$\sum_{i=1}^{I} \sum_{k=1}^{D} X_{M D i} \geq \sum_{i=1}^{I} \sum_{j=1}^{P} X_{D P i}, \forall i$

$\sum_{i=1}^{I}\left(\alpha_{M i} * H_{M D i}\left(t-L_{M D}\right)\right) \leq Z_{M}, \forall i$

$\sum_{i=1}^{I} \sum_{k=1}^{D}\left(\beta_{M i} * \mathrm{H}_{M D i}\left(t-L_{M D}\right)\right) \leq Q, \forall i$

$\sum_{i=1}^{I} \sum_{k=1}^{D}\left(\gamma_{D i} * \mathrm{H}_{M D i}\left(t-L_{M D}\right)\right) \leq R_{D}, \forall i, k$

$\sum_{i=1}^{I} \sum_{j=1}^{P} X_{D P i} \geq R_{D}, \forall i, j$

$H_{M D i}\left(t-L_{M D}\right)>0, \quad \forall k, i$

$H_{D P i}\left(t-L_{D P}\right) \geq 0, \quad \forall j, i$

$Y_{D i}(t-1) \geq 0, \quad \forall i$ 


$$
\begin{gathered}
\sum_{k=1}^{D} Y_{D i(t)} \leq K_{d} \\
X_{D P i}(t)>0, \forall i, j
\end{gathered}
$$

$$
X_{M D i}(t)>0, \quad \forall k, i
$$

$$
Y_{D i}(t)>0, \forall k, i
$$

$$
y d \in\{0,1\} \quad d=1 \cdots k
$$

Top model of the objective functions Eq. 1 the production which is cost by the manufacturer. From the manufacturer to the distribution center transportation costs, distribution centres inventory costs. Among Eq. 2 Distribution Center inventory costs by the distribution centre on a residual inventory plus inventory that is the moment the original manufacturer this time transported to distribution centers for volume minus the moment conveyed by distribution centre traffic to the distribution point composition.

Constraint condition Eq. 3 is the manufacturer's output that cannot over demand for distribution to distribution centers: Eq. 4 is the distribution center of each product volume that should not exceed the manufacturer's production capacity: Eq. 5 represents manufacturers of products from manufacturers to distribution centre traffic which do not exceed the available resources: Eq. 6 from manufacturers to distribution centers distribution centre or less in volume storage capacity: Eq. 7 distribution points for distribution centers is greater than the total demand for storage capacity equal distribution center: Constraint condition Eq. $11 \mathrm{D}$ distribution center inventory distribution center D less than or equal to the potential distribution capabilities.

\section{Distribution center and distribution point model}

$\operatorname{Min} Z_{D P}=\sum_{i=1}^{I} \sum_{j=1}^{P} h_{P i} * Y_{P i}(t)+\sum_{i=1}^{I} \sum_{k=1}^{D} b_{D P i} * H_{D P i}\left(t-L_{D P}\right)+\sum_{i=1}^{I} \sum_{k=1}^{D} f_{p} * F_{P i}$

In which,

$$
Y_{P i}(t)=Y_{P i}(t-1)+H_{D P i}\left(t-L_{D P}\right) .
$$

Subject to

$$
\begin{aligned}
& \sum_{i=1}^{I} \sum_{j=1}^{P} F_{P i} \leq \sum_{i=1}^{I} \sum_{j=1}^{P} X_{D P i}, \forall j, i \\
& \sum_{i=1}^{I} \sum_{j=1}^{P}\left(F_{P i}+Y_{P i}(t)\right) \leq \sum_{i=1}^{I} \sum_{k=1}^{D} X_{M D i}, \forall j, i, k
\end{aligned}
$$




$$
F_{P i} \geq 0, \forall i
$$

$$
H_{D P i}\left(t-L_{D P}\right)>0, \forall j, i, k
$$

$$
Y_{P i}(t-1) \geq 0, \quad \forall j, i
$$

The lower model is primarily studied the issue of cost of distribution point. The objective function Eq. 16 consists of distribution center to the distribution point of transportation cost, and the out of stock cost with inventory cost of distribution point.Among Eq. 17 the inventory cost of distribution point composition by this moment's inventory cost and the cost of traffic volumes from distribution centers to the distribution point.

The constraint condition Eq. 18 is the out of products of distribution point cannot be more than the total demand of distribution point from the distribution center.The constraint condition Eq. 19 refers to the sum of the distribution point's out of stock and in this time of $\mathrm{t}$ the inventory holdings.

\section{Example}

Assume that there are four distribution centers, they distribute products to four distribution points by each other, Special details like table1

Table 1 A manufacturer's supply capacity, market demand and cost

\begin{tabular}{|l|l|l|l|l|l|l|}
\hline $\begin{array}{l}\text { Transport } \\
\text { distance }\end{array}$ & $\begin{array}{l}\text { Fixed } \\
\text { costs }\end{array}$ & P1 & P2 & P3 & P4 & $\begin{array}{l}\text { Delivery } \\
\text { capacity }\end{array}$ \\
\hline D1 & 7462 & 152 & 138 & 254 & 380 & 23 \\
\hline D2 & 5893 & 269 & 101 & 298 & 258 & 19 \\
\hline D3 & 5283 & 83 & 267 & 182 & 308 & 16 \\
\hline D4 & 6031 & 279 & 237 & 245 & 127 & 18 \\
\hline Demand & & 11 & 15 & 7 & 13 & \\
\hline
\end{tabular}

Restructured these distribution centers in the region, discussing whether each delivery is required, determine identify distribution center closing or selling. Thereby reducing the total cost of the supply chain to achieve optimization of distribution networks.

According to the established model, focusing on upstream model, the example is using excel solver tool calculates the distribution center location settings.

Table 2 Building data in Excel, and make each variable's initial value is 0

Table 2 is a variable distribution decision of the manufacturer.

\begin{tabular}{|l|l|l|l|l|l|l|l|}
\hline & A & B & C & D & E & F & G \\
\hline 1 & $\begin{array}{l}\text { Transport } \\
\text { distance }\end{array}$ & Fixed costs & P1 & P2 & P3 & P4 & $\begin{array}{l}\text { Delivery } \\
\text { capacity }\end{array}$ \\
\hline 2 & D1 & 7462 & 152 & 138 & 254 & 380 & 23 \\
\hline 3 & D2 & 5893 & 269 & 101 & 298 & 258 & 19 \\
\hline 4 & D3 & 5283 & 83 & 267 & 182 & 308 & 16 \\
\hline 5 & D4 & 6031 & 279 & 237 & 245 & 127 & 18 \\
\hline 6 & Demand & 11 & 15 & 7 & 13 & \\
\hline 7 & \multicolumn{7}{|l|}{} \\
\hline 8 & $\begin{array}{l}\text { Transport } \\
\text { distance }\end{array}$ & $\begin{array}{l}\text { Operations / } \\
\text { Close }\end{array}$ & P1 & P2 & P3 & P4 & \\
\hline 9 & D1 & 0 & 0 & 0 & 0 & 0 & \\
\hline 10 & D2 & 0 & 0 & 0 & 0 & 0 & \\
\hline 11 & D3 & 0 & 0 & 0 & 0 & 0 & \\
\hline 12 & D4 & 0 & 0 & 0 & 0 & 0 & \\
\hline
\end{tabular}


Finally solves through the Excel linear programming model, obtains the best solution Table 3

\begin{tabular}{|c|c|c|c|c|c|c|c|}
\hline & A & B & $\mathrm{C}$ & D & $\mathrm{E}$ & $\mathrm{F}$ & $\mathrm{G}$ \\
\hline 1 & $\begin{array}{l}\text { Transport } \\
\text { distance }\end{array}$ & Fixed costs & $\mathrm{P} 1$ & $\mathrm{P} 2$ & P3 & P4 & $\begin{array}{l}\text { Delivery } \\
\text { capacity }\end{array}$ \\
\hline 2 & D1 & 7462 & 152 & 138 & 254 & 380 & 23 \\
\hline 3 & D2 & 5893 & 269 & 101 & 298 & 258 & 19 \\
\hline 4 & D3 & 5283 & 83 & 267 & 182 & 308 & 16 \\
\hline 5 & D4 & 6031 & 279 & 237 & 245 & 127 & 18 \\
\hline 6 & Demand & & 11 & 15 & 7 & 13 & \\
\hline \multicolumn{8}{|l|}{7} \\
\hline 8 & $\begin{array}{l}\text { Transport } \\
\text { distance }\end{array}$ & $\begin{array}{l}\text { Operations / } \\
\text { Close }\end{array}$ & P1 & $\mathrm{P} 2$ & P3 & P4 & \\
\hline 9 & D1 & 0 & 0 & 0 & 0 & 0 & \\
\hline 10 & D2 & 1 & 0 & 15 & 0 & 0 & \\
\hline 11 & D3 & 1 & 11 & 0 & 5 & 0 & \\
\hline 12 & D4 & 1 & 0 & 0 & 2 & 13 & \\
\hline 13 & $\begin{array}{l}\text { Transport } \\
\text { distance }\end{array}$ & $\begin{array}{l}\text { Delivery } \\
\text { capacity }\end{array}$ & P1 & $\mathrm{P} 2$ & P3 & P4 & \\
\hline 14 & D1 & 0 & & & & & \\
\hline 15 & D2 & 4 & & & & & \\
\hline 16 & D3 & 0 & & & & & \\
\hline 17 & D4 & 3 & & & & & \\
\hline 18 & Demand & & 0 & 0 & 0 & 0 & \\
\hline
\end{tabular}

It can be concluded that, the best option is to turn off the manufacturer's distribution center D1, then running the other three distribution centers. Can save the cost of D1.

\section{Model analysis}

In the numerical example and established the two models, you can see it's very important in the optimized distribution network of the network design and make a minimum of operational costs.For Two-stage optimization of distribution network model, many scholars adopted many methods,like genetic algorithm, climbing algorithm, integer planning and so on.Here we have not been discussed, in addition to the above example of conclusion we obtain,also we can control the shortage cost.

Caused by information asymmetry and lack of timely makes the shortage cost of distribution point, you can establish a new type of logistics management information system. For manufacturers, distribution centers, distribution points provide a broad platform of information. Assuring that information publicly, and published in a timely manner, can quickly get updated each node of the distribution network, thereby reducing the shortage cost. optimization of distribution network system.

\section{Conclusion}

This paper presents the Demand Uncertainty, distribution network optimization Design model, and analysis for the model, gives a specific example.In the expectation that the distribution network of the production and distribution chain can be coordinated and integrated, and to reduce the total cost of production and distribution chain, and indirectly increase customer satisfaction, thus increase the market response, it's a reference value for achieve distribution network optimization design.

\section{Acknowledgement}

This research was financially supported by college students ' innovation and entrepreneurship projects (no: 2013-69). 


\section{Reference}

[1] Hai-He Jin, Chen Jian, Jun-Chun Zhao. Distribution network optimization model and its solution algorithm for distribution network [A].Journal of Tsinghua University (natural science Edition),2002,(6):0739-0.

[2] Zhang Xun.Genetic algorithm the supply chain level 2 distribution Wang optimize the design of the random planning model[A].Science Technology and Engineering 2005 (12): 23-1819-05.

[3] Li Ye, Chen Yan.Based on a random demand of multi-level Supply Chain network optimization mo-del of research [A]. Computer Integrated Manufacturing System, 2004 (9): S10025-05.

[4] Xiao-Yu Zhao, Ding-Wei Wang. Supply chain optimization model for two-Echelon distribution network [A]. Management Science Journal, 2001 (8): 04-0022-05.

[5] Yuan-Kai Xi, Wu Min. Supply Chain under Stochastic Demand Inventory Control Strategy [A]. Application Research of Computers, 2009 (9): 1001-3695 (2009) 11-4221-02.

[6] Chang-Bing Jiang, Li-Jun Bai. Supply Chain Technology theory and Modeling [M]. Beijing: ChineseCommodity Publishing house, 2009. 